\title{
Research on the Construction of University Departmental Archives Based on the Perspective of Awareness-Formation-Use
}

\author{
Lin Jiang1,2 \\ ${ }^{1}$ Yancheng Teachers University, Yancheng, China \\ ${ }^{2}$ Nanjing University of Aeronautics and Astronautics, Nanjing, China \\ Email: jiangl@yctu.edu.cn
}

How to cite this paper: Jiang, L. (2022). Research on the Construction of University Departmental Archives Based on the Perspective of Awareness-Formation-Use. Journal of Human Resource and Sustainability Studies, 10, 67-76.

https://doi.org/10.4236/jhrss.2022.101005

Received: January 27, 2022

Accepted: March 5, 2022

Published: March 8, 2022

Copyright () 2022 by author(s) and Scientific Research Publishing Inc. This work is licensed under the Creative Commons Attribution International License (CC BY 4.0).

http://creativecommons.org/licenses/by/4.0/

\begin{abstract}
In this paper, in view of the current situation that frequent rotation of college administrative staff affects the connection of work as well as less job training and lack of section files, the benefits of section file construction are discussed, and the ways of section file construction are actively explored, which are the cultivation of section file formation awareness, formation process and usage method, respectively, in order to provide college administrative staff with quick understanding of work, in-depth work, innovative work and provide effective solutions to summarize their work.
\end{abstract}

\section{Keywords}

Universities, Section Archives, Archival Awareness, Archival Formation, Archival Use

\section{(c) (i) Open Access}

\section{Introduction}

In universities, we are familiar with the personnel files, clerical files and student files. Personnel files are personal files, which record all the important points and deeds of individual staff members, and are generally used when there are major changes such as personal promotion, transfer, political examination, review, retirement and death; clerical files are public files, which record the beginning and result of all the events that happened in universities, i.e. there are beginning documents and result documents as well as rosters, records, amounts and other attached materials. They are generally used for searching and copying to prove the authenticity and validity of a certain material; student files are also personal files, which record the important points and deeds that happened during the 
students' school years, and are the continuation of the personal files in the pre-school and compulsory education stages. The above three types of records have relatively fixed specifications and requirements, what to record, how to record, standardized and uniform forms, standardized and uniform bindings, and so on. But there is a kind of file that we seldom mention or hear about, and that is the section file. Departmental files are the beginning, result and process materials of all the work of the department, and are a useful supplement to the above three kinds of files, showing the context more clearly.

In my survey, I found that section chief positions in universities rotate frequently among themselves. The number of people and the rotation of ordinary, how to maintain the continuity and effectiveness of the work, has been a headache for college management workers. Therefore, all the big middle level are willing to enable skilled hands, but not willing to use new people, because familiar with the work of the section chief will be more efficient and effective than unfamiliar with the work of the section chief, and the rotation will be staged during the "snatch" war. Competitive recruitment is a good thing to improve the quality of section chiefs, but the "snatching" war reflects a problem that the section files are not sound or not available, which has become the shackles of university administration.

The training for section chiefs on administrative management in universities is very little, and basically the mode adopted is to learn from the division chiefs, whose style of dealing with people often determines the direction of a division or several sections. Generally, at the beginning, the division chiefs are asked to familiarize themselves with the documents, standardize the workflow, abide by the professional ethics, and enhance the service concept, but rarely do the division chiefs give their opinions on the construction of the division files.

Every social behavior of every person will produce corresponding archives, and without archives perhaps nothing can be done. The Chinese library science, intelligence science and archives are disciplines of collecting and organizing books and documents, disseminating and exchanging information and knowledge, preserving and passing on culture and memory, and are important parts of the philosophy and social sciences with Chinese characteristics ( $\mathrm{Si}$, Chen, Wang, \& Shu, 2020). 2021 saw the promulgation and implementation of the new Archives Law, which opened a new chapter of archives governance according to law, and the guiding ideology of promoting the construction of archives governance system and enhancing the effectiveness of archives governance has been running through the "14th Five-Year Plan". The guiding ideology of promoting the construction of archival governance system and enhancing the effectiveness of archival governance has been running through the National Archival Development Plan for the 14th Five-Year Plan, and has become a hot issue of concern to the government, academia and practice (Zhang \& Li, 2021). The main contradiction of archival work in the new period is between "social development" and "archival development" (Wu \& 
Gao, 2018). The concept of "big archives" proposes to include all archives with preservation value into the archives and adopt "multiple archives in one" to improve the management level and service capacity (Lin \& Zhang, 2018). Colleges and universities should reflect on the current problems of backward archival awareness, blurred division of labor, and insufficient archival intervention, so the author addresses these shortcomings to discuss the benefits and ways of building section archives (Liu, 2018).

\section{The Benefits of Departmental Archiving}

The setting of departments and sections in colleges and universities is relatively fixed and slowly split, why do you say so? For example, the president's office, organization and personnel department, finance department, audit department, propaganda department, state capital department, scientific research department, academic affairs department, student affairs department, logistic support department, labor union, etc. are the departments that most universities have. As the depth and breadth of work increase, organization and personnel department splits into organization department and personnel department, student affairs department splits into academic affairs department and enrollment and employment department, scientific research department splits into social science department and science and technology department and regional The Division of Scientific Research was split into the Division of Social Science and Technology and the Division of Regional Services, etc. For example, the state approved the establishment of 30 teacher teaching development demonstration centers in 2012, some of which are co-located with the Personnel Office, some with the Academic Affairs Office, and some are independent offices; in 2017, universities attached importance to teacher morality and have set up the Department of Teacher Work of the Party Committee; bidding work is becoming more and more important, and a bidding work division has been established. So what are the benefits of section file construction? The author entered the keywords of "section file" and "role" in "China Knowledge Network" and got 13 published papers. The abstracts of these 13 papers were entered into Gooseeker software for word separation, word selection and matching, forming a keyword cloud map of the role of section files, as shown in Figure 1.

According to the keyword cloud map of the role of section files extracted from the literature, the author summarizes the benefits of section file construction in four aspects, which can quickly understand the work, go deeper, innovate and summarize the work, as shown in Figure 2.

\subsection{You Can Learn about the Work}

Section files can understand the work reflected in the access to archival information and business processes shown in the files. Since the division and section are relatively fixed, the existing work is the expansion on the basis of the original work, pioneering work is rare, especially in the first year of entering a new job, 


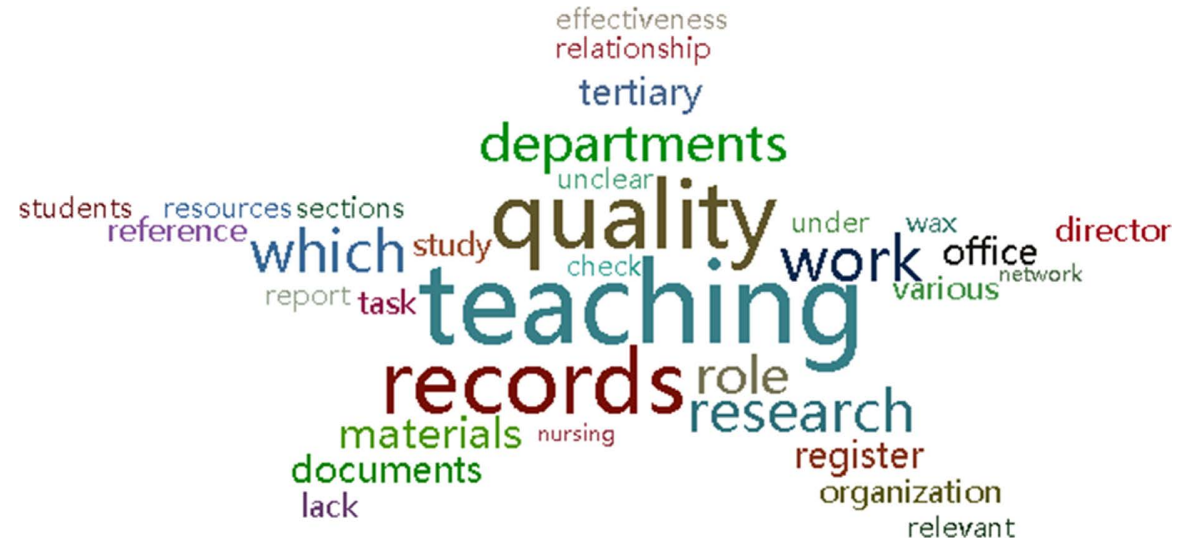

Figure 1. Keyword cloud map of the role of section archives based on literature

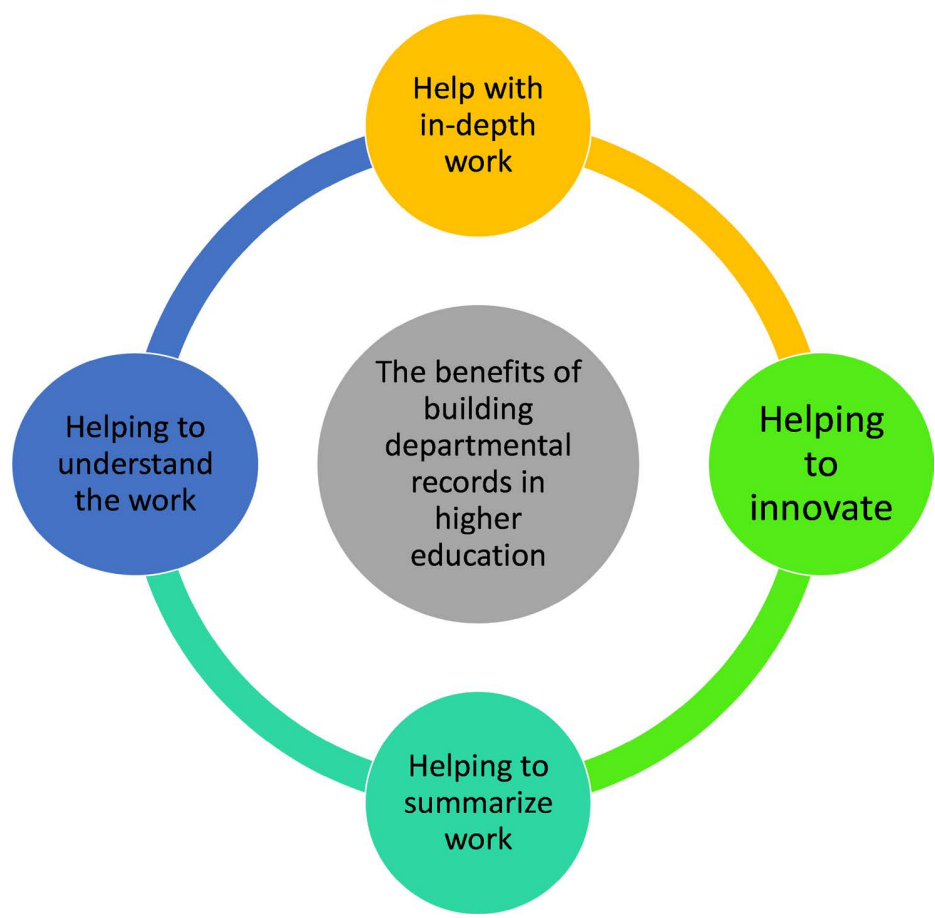

Figure 2. Benefits of building departmental records.

because it is unfamiliar, so generally will take the same practices and requirements as before. At this time, by checking the section files, you can quickly understand the work through the following six dimensions: first, you know what the work actually does and what things are done; second, you know where the work comes from, and where it is assigned, and where it is finally attributed; third, you know the time point for completing the work; fourth, you know the resources for completing the work; fifth, you know the methods and procedures for completing the work; sixth, you know the results of the past work and perhaps have an important impact on the present work.

\subsection{Can Work in Depth}

Section archives can go deeper into the work reflected in the strengthening of 
work, sorting out work problems, analyzing work, and supervising work. The biggest difference between departmental files and clerical files is the process materials. Clerical files usually have beginning materials and result materials, but departmental files not only have beginning materials and result materials, but also process materials. All the materials collected by the section chiefs in the university can be used as future backup materials to enter the section files, which have detailed process and traces to be found, such as the declaration process, the evaluation process, the voting process, the minutes of meetings, expert scores, sealed test papers, interview videos, etc. Some involve confidentiality must also be entered into the safe, kept by a special person, but some do not involve confidentiality. These detailed process materials undoubtedly play a very good role in the rapid depth of work to assist. In addition, the paper files need to go to the archives, after many approval procedures, section files with the return, easy to browse, approval procedures are relatively simple or not, which also provides a convenient in-depth work. For example, the text of the contract, many contracts and agreements are in several copies, if the section files have the text of the contract or agreement, then the assessment of the contract or agreement or treatment will be much simpler to cash, sometimes cannot find the contract or agreement is a very troublesome thing, or to the paperwork files to find copies will also be very troublesome.

\subsection{Can Work Innovatively}

Section archives can do innovative work by reengineering business processes, reviewing and improving the quality of work, conducting research on work, teaching archives, and reporting on archival publicity. On the basis of understanding the work and in-depth work, we can do innovative work. Section chiefs can start work innovation from the following three points: first, the revision of past documents, contract texts, etc., adding new era requirements and management norms; second, the improvement of past work procedures and methods, more conducive to good service work; third, adding new work content according to past work content, creating a good and positive competition environment, and promoting the work of universities to cross a new level. Innovative work is also very dependent on the section files, because the introduction of any policy of the university must have continuity, not copying a document to take root and blossom, but must be closely linked with the history and situation of each university.

\subsection{Can Summarize the Work}

Section files can summarize the work is reflected in the rearrangement of work materials according to the requirements of different departments, the exchange of files and the construction of archival networks, etc. With the past section files and new section files, the section chiefs in the process of organizing the files is to sort out and summarize the work again, so they can check the leaks and fill in 
the gaps. Some work just has the beginning documents but no result documents, then naturally they should go to find the result documents; some work process materials are missing, which must be where there is a mistake; some work result documents are not signed by the leaders, then they can go to supplement the signatures; some work has the result document, but the funding is not yet in place, then you can go to supplement the funding; some work has been a breakthrough relative to the previous year, but need summary data to support, then you can according to the material statistics out of detailed, complete and credible data; some work still needs to be improved, then you can write the next year's work ideas according to the material, and so on. Therefore, section chiefs with section files can always write rich work summaries supported by data and detailed processes.

\section{The Way of Departmental Archives Construction}

Individual digital archiving behavior is strongly correlated with their personal factors (age, Internet age, education level) and archiving awareness and archiving ability, among which archiving awareness and archiving ability play a mediating role between personal factors and archiving behavior, so the cultivation of archiving awareness and ability of college administrators is particularly important (Guo, 2018). This paper examines three aspects of the development of awareness of section archive formation, the development of the process of section archive formation, and the development of the process of section archive use.

\subsection{Cultivation of Awareness of Departmental File Formation}

The section chiefs working in colleges and universities are the ones who add bricks to the educational cause and are engaged in what is by no means just a personal cause, but a cause for all. I believe that every new college administrator should establish a sense of section archives, because we have to be responsible for our work, leaving traces for future reference, and more importantly, leaving available reference materials for future generations, so that the school business can flourish. We should consider what kind of section files will be formed in the end while completing various administrative tasks in our mind, which will make our collection and organization work more targeted and with a holistic view. Awareness of the whole picture is crucial for college section chiefs. In other words, without an awareness of the whole picture you cannot write plans, procedures, and documents. With section file awareness, it is possible to produce section files. Section archives awareness can be cultivated in the following four ways: first, professional lectures, inviting archives experts to conduct awareness training, and also regular pushing of practical archives knowledge in the form of videos, cartoons, motion pictures, short articles, etc. by using network media such as WeChat public number; second, visiting and learning, experiencing the achievements of section archives on the spot to enhance the awareness of the value of archives and archives themselves; third, reinforcement by the director, 
the directors of each Fourthly, the assessment and scoring is to incorporate the quality evaluation of departmental archives into the general assessment and scoring system of the university, and the archives will conduct the assessment and scoring in a fair, just and open manner, which promotes the institutionalization, standardization and scientificization of archives, enhances the status of archives, and promotes the balanced and rapid development of university departmental archives (Zhu, 2018). It also promotes the balanced and rapid development of archival work in university departments (Zhao, 2021).

\subsection{Cultivation of the Process of Forming Departmental Records}

The constructability of national identity and the relevance of archives to national culture and politics are the prerequisites for the role of archives in national identity, and the intrinsic logic lies in the fit between the characteristics of national identity and archives. Archival management is a highly organized and disciplined task, which requires strict compliance with the Archival Law, the Secrecy Law and the policies of the Party, the State and the universities, as well as improved political awareness. In addition to recording the basic archival information, the relevant staff should also increase the initiative of acquiring knowledge information and expand the scope of archival information (Gao \& Wu, 2021).

The process of forming section files is divided into six steps: classification, collection, collation, review, gluing and storage. Classification is the first and most critical step. Classification is to prepare a working directory, which is important work, which items to divide, clear organization, clear boundaries, and clear logical relationships. The second step is to collect, can be the teacher's personal declaration materials, but also other sections of the audit materials, and many summary materials, annex materials, etc., a variety of materials to be collected in a certain order, so this step, the order is the most important, belongs to the small classification. The third step is to organize, the work process is simple to organize, the end of the work should be carefully and comprehensively organized, whether the material is complete and the order of arrangement is the focus. The fourth step is to review. Review is to brainstorm, break through the limitations of one's thinking. The fifth step is glued, why should be glued? Because the glued material is not easy to scatter, like a book with a directory, page number, cut after the same size, more neat and beautiful, easy to save, this step is the most important layout, a good layout is more convenient to find. The sixth step is to store, storage location, although the section, but there is also delicate, this step focuses on the order and display environment, different section chiefs have different discharge order habits, different section display cabinets and other environments are not the same, but as far as possible to do neat and beautiful, dry and moisture-proof, easy to find.

\subsection{Cultivation of the Process of Using Departmental Files}

Since the departmental archives have been formed and have so many benefits, 
the next step is to improve the efficiency of their use. The author believes that the following four points can be used to develop the process of using the departmental files: First, the files are borrowed and returned, since they are files, they cannot be lost in any place outside the department, and there are usually no copies of the departmental files, they are all orphaned, and there are no detailed approval procedures, so the borrowers should develop the good habit of borrowing and returning them; second, the formation of the use mechanism, we say that the directors will generally ask newcomers to familiarize themselves with the work. Then the newcomers can be given a week to view the section files, and after a week to report in detail the history of each work, and after a month to report in detail the ideas of each work; Third, the formation of a compilation of documents, so that the section chiefs from the section files to find work-related documents and photocopies, the formation of a compilation of documents, a copy of the members of the section, to facilitate learning and better completion of the consultation and interpretation of the work for the staff; Fourth, the formation of a compilation of documents. Fourth, focus on professional ethics, maintaining the security of national ideology is an important political responsibility of archival work, the details of the content viewed confidentiality is not leaked (Chen, 2021).

Based on the above study based on archival awareness, formation and use, we use Figure 3 in order to understand the section archival construction pathway more visually and clearly.

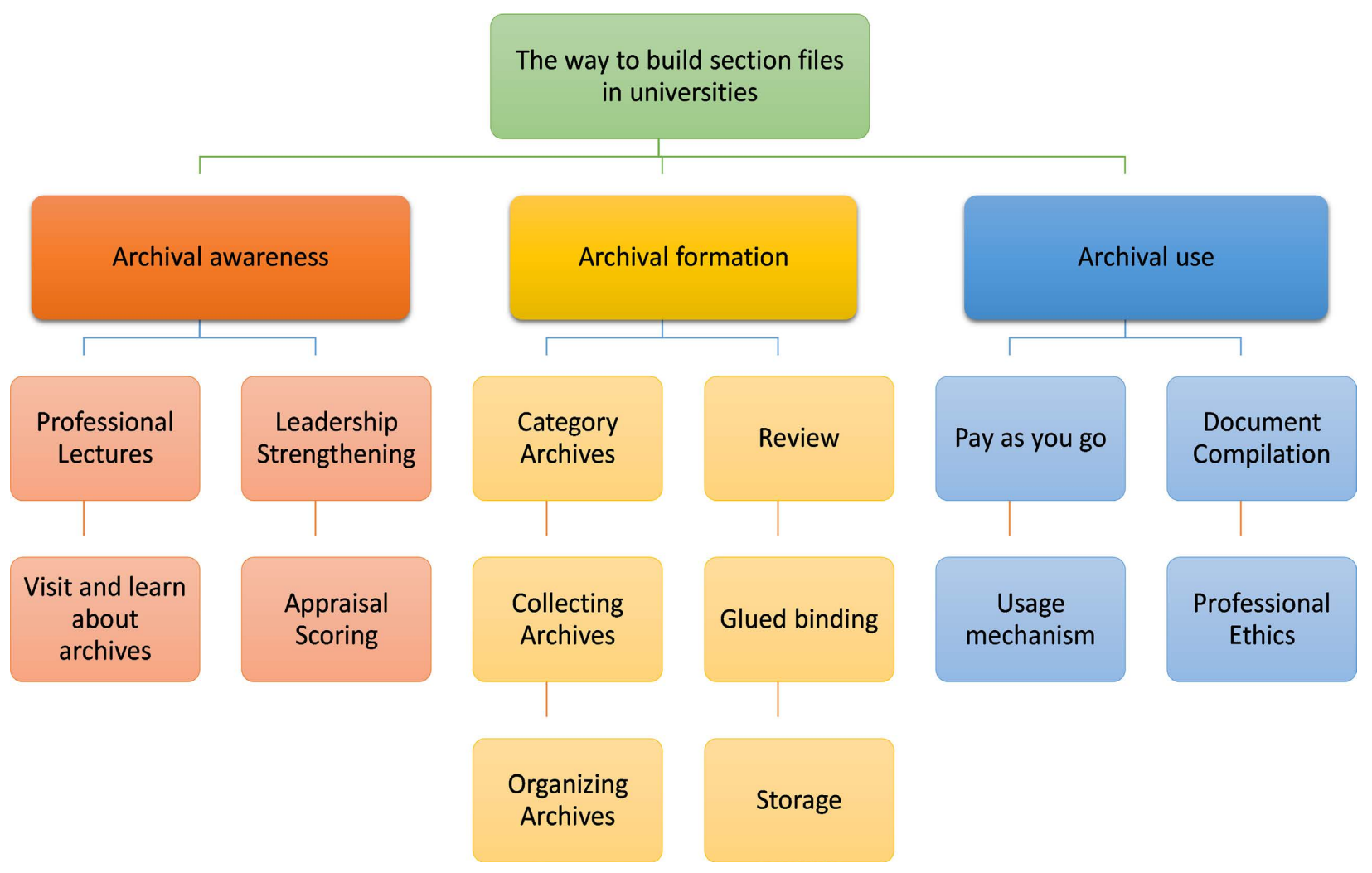

Figure 3. Section archive construction pathway. 


\section{Conclusion}

Section archives have never been included in the work plan or work summary in college administration, and we talk about target management, performance management, etc., with little or no mention of archives management, which has been a neglected problem for a long time, but it is an important basis for improving work style and work innovation, especially the work connection in the process of rotation, which relies more on the construction of section archives. Whether electronic files or paper files, administrators in universities, especially section chiefs, have the responsibility and obligation to form section files to provide detailed records and materials for the development of education in universities. This paper firstly discusses the benefits of section archives, which can be used to understand work, deepen work, innovate work and summarize work. Secondly, the paper explores the ways to build section archives based on the three aspects of "archival awareness - archival formation - archival use", which is also the innovation point of this paper. Archival awareness can make the departmental archives from nothing to something; archival formation can make the departmental archives from irregular to standard, from one-sided to comprehensive, from unclassified to classified; archival use can make the departmental archives better produce work value, and further enhance archival awareness and improve the efficiency and effectiveness of archival formation. Therefore, archival awareness, archival formation and archival use are inseparable parts of archival work, and they influence each other, complement each other and improve each other. If we want to build departmental archives, archival awareness, formation and use are indispensable. Finally, the method of constructing section archives in this paper has been practically applied in the personnel department of $Y$ university, and the effect is very good. The materials in the personnel department are very large and important, and if they are not organized into section files in a timely manner, it is occasionally difficult to find them as the personnel handling them change, and in the absence of files, it is very difficult to find them even if they are available. Based on the methods in this paper, the personnel department of $\mathrm{Y}$ university has established rules and regulations for section files such as objectives, tasks, assessment and use, and also conducts file display and evaluation as well as opinion activities among sections at the end of each year, which has greatly improved the efficiency and effectiveness of personnel work. This paper provides a very good research idea for the popularization of section files in colleges and universities, but it does not provide assessment data in terms of section files. In the future, we will collect file data and try to use quantitative methods to start research on file assessment in terms of file work.

\section{Acknowledgements}

1) Jiangsu Province Education Reform and Development Strategic and Policy Research Major Project: Jiangsu high-level teacher team construction research, Project No. 202000206. 
2) Project of Jiangsu Provincial Education Department: Research on talent management innovation of universities based on big data in the context of “double first-class", Project No. 72031941028A.

\section{Conflicts of Interest}

The author declares no conflicts of interest regarding the publication of this paper.

\section{References}

Chen, H. (2021). On the Responsibility of Archival Work to Maintain Ideological Security and Its Realization Path. Archives Science Study, No. 5, 4-9.

Gao, S. N., \& Wu, J. H. (2021). Archives and National Identity: Theoretical Basis, Role Dimensions and Realistic Path. Archives Science Study, No. 6, 35-40.

Guo, X. M. (2018). An Empirical Study on the Mediating Effect of Personal Digital Archiving Behavior-A Random Questionnaire Survey Based on Chinese Internet Users. Archives Science Bulletin, No. 5, 17-25.

Lin, L., \& Zhang, S. Y. (2018). Research on Collaborative and Innovative Management of University Cultural Centers from the Perspective of "Big Archives". Zhejiang Archives, No. 11, 22-24.

Liu, X. (2018). Optimization Strategy of University Infrastructure Archives Management under the New Normal. Shanxi Archives, No. 6, 38-40.

Si, L., Chen, C., Wang, Y. W., \& Shu, C. (2020). Comparative Analysis of Research Hotspots in Library Intelligence and Archives Management Disciplines at Home and Abroad from 2014-2018. Books and Intelligence, No. 1, 75-82.

Wu, J. H., \& Gao, S. N. (2018). On the Main Contradiction of Archival Work in the New Era. Archives Science Bulletin, No. 5, 4-8.

Zhang, W. D., \& Li, S. T. (2021). Archival Governance for Modernization: An Overview of "Archival Governance" Research in 2021. Information and Documentation Services, No. 43, 19-22.

Zhao, S. (2021). Practice and Innovation of Assessment and Evaluation Mechanism of Archival Work. Shaanxi Archives, No. 4, 31-33.

Zhu, C. N. (2018). An Effective Way to Enhance the Archival Awareness of Contemporary College Students. Archives Management, No. 6, 93-98. 